You can find the original print version in below link

DOI: http://www.springerlink.com/content/r282201465372g67/

\title{
A Theoretical I nvestigation of the Emerging Standards for Web Services
}

Karthikeyan Umapathy and Sandeep Purao College of Information Sciences and Technology, Penn State University University Park, PA 16802

\{kumapathy, spurao\}@ist.psu.edu

\section{Keywords:}

Service-Oriented Computing, Web Services, Web Services Standards, W3C web services, Semantic Web Services, ebXML, Standards Stacks, Layered Models, Language-Action Perspective, Reference Framework

(C) 2006. K. Umapathy, S. Purao. 


\title{
A Theoretical I nvestigation of the Emerging Standards for Web Services*
}

\begin{abstract}
Currently, standards for web services are being developed via three different initiatives (W3C, Semantic web services and ebXML). To the best of our knowledge, no theoretical perspectives underlie these standardization efforts. Without the benefit of a strong theoretical basis, the results, within and across these initiatives, have remained piecemeal. We suggest 'Language-Action Theories' as a plausible perspective that can effectively define, assess and refine web services standards. In this paper, we first investigate the existing initiatives to identify commonalities that point to theories of 'Language-Action' as an appropriate theoretical basis for web services standards. Next, we adapt work from these theories to develop a comprehensive reference framework for understanding web services standards. Finally, we use this reference framework to assess the three initiatives, and analyze the findings to provide insights for future development and refinement of web services standards.
\end{abstract}

\section{Keywords:}

Service-Oriented Computing, Web Services, Web Services Standards, W3C web services, Semantic Web Services, ebXML, Standards Stacks, Layered Models, Language-Action Perspective, Reference Framework

\footnotetext{
* The authors would like to thank editors for this special issue and two anonymous reviewers for helpful comments on an earlier draft of this paper, and M. Hopkins for several editorial suggestions.
} 


\section{Introduction}

Standards are an important component for web services because they facilitate interactions among applications within and across organizations. They must, therefore, cover a wide array of concerns such as messaging, publishing, discovering, and composing. Constructing a single, monolithic standard that encompasses all these is enormously difficult. Ongoing work on web services standards ${ }^{1}$ has, therefore, developed separate core standards for publishing (WSDL (WSDL, 2001)), finding (UDDI (UDDI, 2005)), and binding (SOAP (SOAP, 2003)). Such 'separation of concerns' is a necessary attribute of web services standards, which can be achieved by segmenting the standards-space into different 'layers' (similar to (Kreger, 2001)). The resulting 'standards stack' ${ }^{2}$ segregates the standards space into multiple layers which can provide boundaries for development and use of standards. An analogy can be seen in the OSI seven-layer model (OSI, 1994), which separates networking technologies into a seven-layer abstraction. A standards stack for web services can perform a similar function.

An important concern, however, is the identification of appropriate layers in this stack. Without an agreement about these layers, development of standards in this space remains a piecemeal effort. For example, standards that cross layers, such as WS-BPEL (WS-BPEL, 2005) and WS-CDL (WS-CDL, 2004), have been proposed over the last few years. Competing standards within a layer have also been proposed, such as WS-coordination (WS-CF, 2004) and WS-CDL (WS-CDL, 2004), causing confusion for information systems developers.

Our review of prior work shows that holistic efforts to identify these layers have been lacking. Prior work has either produced compilations of existing standards (Mukhi, Plebani,

\footnotetext{
${ }^{1}$ Appendix A shows a list of standards proposed for web services following different initiatives.

2 The term 'web services stack' refers to a 'stack of web service standards' (Sleeper \& Robins, 2001).
} 
SilvaLepe, \& Mikalsen, 2004) or has been driven by considerations of adoption of standards (Gosain, 2003). Without the benefit of a holistic framework guided by appropriate theories, work in this space has suffered from false starts (WS Arch, 2005; WSCI, 2002).

An appropriate theoretical framework is found in the stream of research known as Language-Action Perspective (LAP), which maps well to the core of service-oriented computing, i.e., ‘communication' (Lemniotes, Papadopoulos, \& Arbab, 2004). LAP was originally developed in the context of human actors communicating with one another to achieve organizational goals (Lyytinen, 2004). We argue that this research stream can be adapted and applied to the web services standards space. Our objective in this paper is to adapt research from the Language-Action perspective to construct a reference framework for the web services standards space, and demonstrate how it can be used to assess existing standards or develop new standards. The paper starts by investigating how the three existing initiatives operationalize core web services concepts. Next, by adapting important concepts from LAP, we develop a reference framework for the web services standards space. We then demonstrate how the reference framework can be used to assess the existing initiatives. Finally, we discuss implications for refinement and development of future standards.

\section{Web services as the realization of service-oriented computing}

The service-oriented computing (SOC) paradigm ${ }^{3}$ is currently being realized through three different initiatives. The first represents a major effort from the World-Wide Web Consortium (W3C), which builds on the premise that web services may be defined in a

\footnotetext{
3 Service-Oriented Computing (SOC) refers to a re-conceptualization of software to its essence, that of service (Papazoglou \& Georgakopoulos, 2003; Turner, Budgen, \& Brereton, 2003). In an SOC environment, applications are recast as "services." They declare their functional and nonfunctional requirements and capabilities in an agreed upon, machine-readable format (Curbera, Khalaf, Mukhi, Tai, \& Weerawarana, 2003).
} 
programmatic manner so that companies can use them to integrate their operations (WS Arch, 2005). The second represents an effort that is backed by the research community interested in a vision of the Semantic Web that augments web services with semantic components (Paolucci \& Sycara, 2004). The third represents an effort by the Organization for the Advancement of Structured Information Standards (OASIS) in conjunction with the UN as a way to build upon existing Electronic Document Interchange (EDI) infrastructure to facilitate global trade (ebXMLReq, 2001).

\subsection{Alternative instantiations}

The three initiatives conform to the same basic operations (publish, find and bind) ${ }^{4}$ and roles (service provider, service discovery agency, and service requestor) (Manes, 2003; Papazoglou \& Georgakopoulos, 2003). Each, however, operationalizes these with slight differences. We explain and contrast the three with an online travel agent example:

"[WSClient], a potential customer, queries a business registry for online travel agent. The registry returns a list of online travel agent services. [WSClient] selects [TAService] service, which is most fitting to its requirements and then binds to that service.”

\section{The W3C initiative}

To realize our example scenario using the W3C initiative, [TAService] would create a Web Services Definition Language document (WSDL, 2001) to describe its service interfaces, and publish it in the Universal Description, Discovery, and Integration registry (UDDI, 2005). [WSClient] will query the registry for services, which provide online travel agent capabilities. [WSClient] would select a service which meets its requirements. Assuming that [WSClient] selects [TAService], it would then bind its application to [TAService]. [WSClient] will generate

\footnotetext{
${ }^{4}$ A native capability of SOC applications is the ability to describe themselves (publish), locate service partners (find), and invoke these services as required (bind). These three operations provide the basic building blocks of a service-oriented architecture (Curbera et al., 2003).
} 
Simple Object Access Protocol (SOAP, 2003) messages conforming to [TAService]'s service declarations, and invoke [TAService]. Both [WSClient] and [TAService] will now exchange messages to communicate.

\section{The semantic web services initiative}

The key difference between the W3C initiative and the semantic web services initiative is that the first depends on a syntactic description of web services, whereas the second utilizes more semantic descriptors derived from the OWL-based Web Services Ontology (Ankolekar et al., 2001). To realize our example scenario using Semantic Web Services, [TAService] would create a service profile of its capabilities using the semantic descriptors. The service profile contains a service model that describes how to interact with the service, and a service grounding that maps the information exchanges described in the service model into actual messages (Ankolekar et al., 2001; Paolucci, Sycara, Nishimura, \& Srinivasan, 2003). The service profile is then published in a Service Registry. [WSClient] will query the Service Registry to find a required service, and when found, use its service grounding to bind the selected service. Assuming that [WSClient] selects [TAService], both services can then generate messages to communicate.

\section{The ebXML initiative}

Unlike the first two, the ebXML initiative builds on existing EDI standards (ebXML, 2005) to specify the ebusiness XML language that globally distributed business partners can use to signify their compliance with minimum requirements for trading and conducting business (ebXML, 2005). The example scenario is realized following the ebXML initiative in the following manner. [TAService] would request the Business Process Specification Schema (BPSS) (ebBPSS, 2001) from an ebXML registry (ebRS, 2002) and populate it with its own capabilities that describe its implementation of an online travel agent service along with a 
Collaboration Protocol Profile (CPP) (ebXML-CPPA, 2002) that specifies the electronic interactions it can participate in. [TAService] will then submit the BPSS and CPP, i.e., its business profile to the ebXML registry. When [WSClient]'s query returns [TAService] as a potential business partner, it can download [TAService]'s business profile from ebXML registry. Both [TAService] and [WSClient] may then agree to conduct business (using their CPP), and will produce a Collaboration Protocol Agreement (CPA). Once the CPA is in place, [TAService] and [WSClient] are said to possess the required trading partner information, and may engage in conducting business electronically using a messaging service that is part of the ebXML specification (Rawlins, 2002).

\subsection{Commonalities across instantiations}

The three initiatives are similar, yet different from one another in their vision because of the different challenges they see at the core of the web services paradigm. For W3C, the key challenge is providing a set of application programming interfaces (APIs) that will allow existing applications to communicate with each other over the web (WS Arch, 2005). For the semantic web services research community, the challenge lies in describing and discovering web services not only syntactically but also semantically (Paolucci \& Sycara, 2004). The third, OASIS, views the core challenge as developing a framework that utilizes existing EDI infrastructure. It, therefore, provides a consistent and uniform manner for exchange of electronic business data for B2B and B2C environments (ebXML-Req, 2001). Over the years, these three initiatives, which started as separate endeavors, have interacted with one another further emphasizing their 
commonalities $^{5}$. Figure 1 highlights the commonalities among the three initiatives.

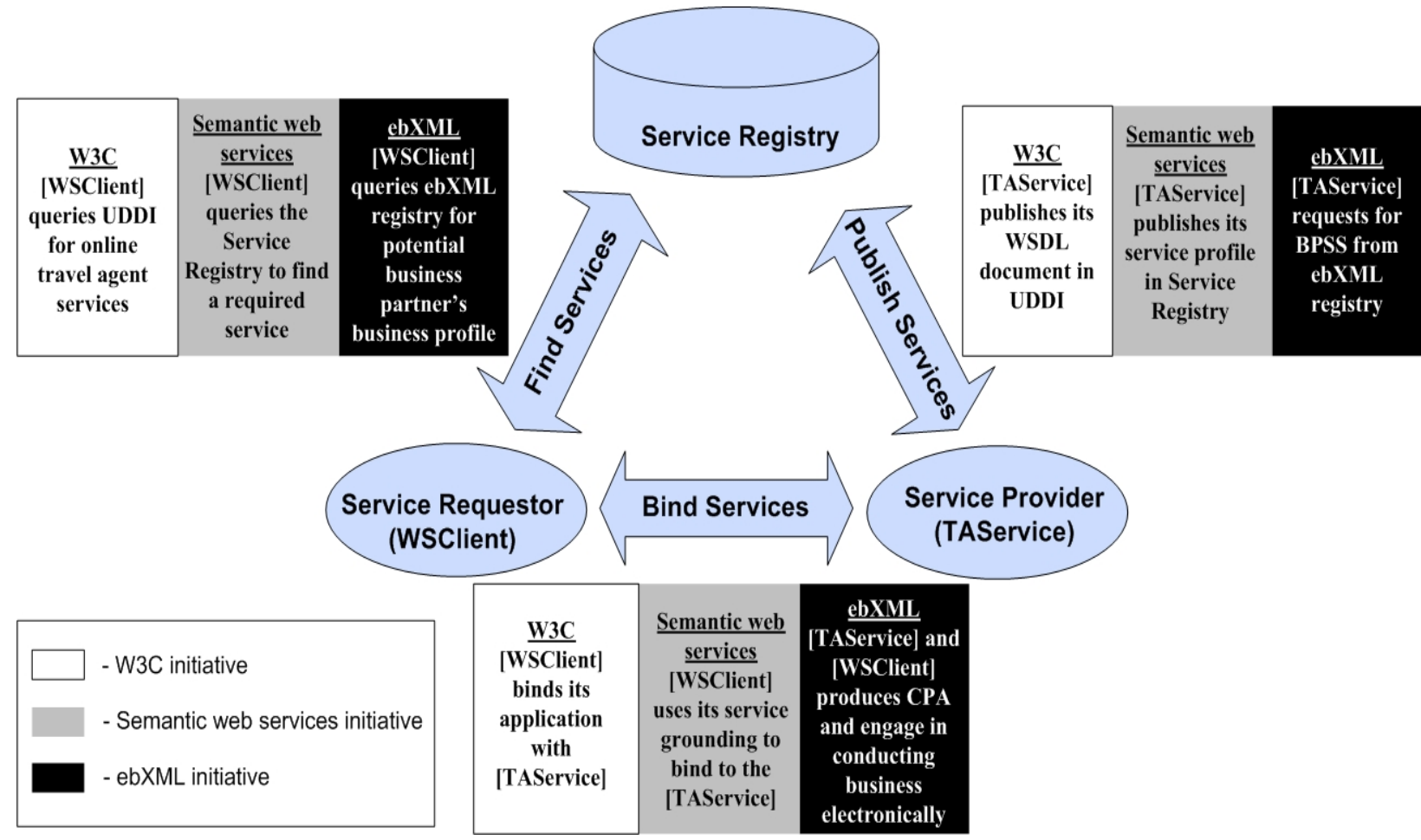

Figure 1: Comparing alternative instantiations with the travel agent scenario

The figure shows that 'communication' is at the core of the service-oriented computing paradigm (Lemniotes et al., 2004) - it is used to publish, find and bind services. The mechanism used to accomplish these actions is communication (e.g., publishing a service in a UDDI corresponds to the action of 'advertising available capabilities'). Communication, thus, represents 'action-taking' in the realm of web services and includes actions such as: (a) advertising available capabilities, (b) locating partners, (c) establishing commitment, (d) negotiating contract terms, (e) entering into a contract, (f) carrying out a transaction, (g) performing an exchange, (h) carrying out processes, (i) establishing trust, and (j) establishing relationships. These activities closely correspond to business activities that increase in time span

\footnotetext{
${ }^{5}$ For example, the W3C has a working group on semantic web services (WS SWSIG, 2002). The UDDI standard, initially developed by OASIS (OASIS, 2005), is now part of the core W3C standards, and the ebXML standard advocated by OASIS (ebXML, 2005) is being integrated within the W3C efforts (WS Activity, 2005).
} 
(from facilitating single interactions with business partners to carrying out processes that include multiple interactions to facilitate business relationships that may include multiple processes). This view of communication and language is different from the traditional database perspective, which views language as a mechanism to record facts from the universe of discourse (Brodie, Mylopoulos, \& Schmidt, 1984; Navathe, Elmasri, \& Larson, 1986). The next section builds on this perspective to identify a theoretical perspective for the web services standards space.

\section{A theoretical framework for the web services standards space}

The two arguments above, (a) communication as action, and (b) emphasis on business activities, lead us to suggest Language-Action Perspective (LAP) as an appropriate theoretical perspective for the web services standards space. Following LAP, we can view information systems as actors, i.e., communicative social entities, with different roles, knowledge, and processes (Klein \& Huynh, 2004), engaged in performing business activities A number of frameworks (e.g., SAMPO (Auramaki, Lehtinen, \& Lyytinen, 1988) and DEMO (Dietz, 1994)) have been constructed on this foundation for modeling of business activities as communicative actions.

The choice of LAP as a theoretical perspective also meets the criteria for theory selection suggested by Holmstrom and Truex (Holmström \& Truex, 2001): (a) selected theory’s historical context, (b) selected theory's sensitivity towards details of the phenomenon under study, (c) selected theory's impact on the choice of research method and (d) selected theory's contribution to cumulative theory-building.

The first criterion is met by the historical application of LAP to message-oriented phenomena. Other information systems based on LAP theories include Coordinator (Winograd \& Flores, 1986), SAMPO (Auramaki et al., 1988), Action Workflow (Medina-Mora, Winograd, 
Flores, \& Flores, 1992), DEMO (Dietz, 1994), MILANO (De Michelis \& Grasso, 1994), and BAT (Goldkuhl, 1996). These systems provide a historical lineage that makes LAP theories appropriate for application to the new domain of web services. The second criterion ensures that the selected perspective focuses on appropriate constructs. LAP theories do, indeed, focus on communication instead of data (Verharen, Dignum, \& Weigand, 1996) following the constructs suggested by theories of speech acts, hermeneutics and sociology of knowledge (Goldkuhl \& Lyytinen, 1982). The third criterion, which describes how the selected theory impacts the choice of research method, is largely inapplicable in the context of this work because our research method relies on the conceptualization of a new reference architecture, and an analysis of existing standards as a validation mechanism. The final criterion assesses whether the selected theoretical perspective would contribute to cumulative theory-building in the target domain. LAP views an organization as a network of interrelated conversations (Aakhus, 2004) similar to actions performed by web services in concert with others. This perspective has been largely absent in web services. By suggesting this perspective, our selection directly contributes to theory-building in the target domain of web services standards.

\subsection{A brief review of research on the language-action perspective}

The use of Language-Action perspective (LAP) for information systems can be traced to Flores and Ludlow (Flores \& Ludlow, 1980), who argued that human beings are linguistic beings and act through language (Schoop, 2001). LAP formulates a norm-based and interpretive alternative of how language is constituted in social life to analyze its implications for the design of information systems (Auramaki et al., 1988; Goldkuhl \& Lyytinen, 1982, 1984; Hirschheim, Klein, \& Lyytinen, 1995; Lyytinen, 2004). It conceives of the use of information systems primarily as a medium or tool for communication (Goldkuhl \& Lyytinen, 1982) drawing upon 
linguistic and social rules that govern the use of language (Goldkuhl \& Lyytinen, 1984). It is, therefore, not so much centered on perfecting computational models and techniques. Instead, it seeks to explain and understand relations between computational phenomena and social behaviors that are embedded in or enabled by information systems (Lyytinen, 2004). The Language-Action approach is, thus, based on the premise that much in organizations is performed through language, i.e., communication is primarily action which, in turn, facilitates coordination and interaction (Ljungberg \& Holm, 1997).

An action view on language and communication for the analysis of business activities is, thus, the essence of LAP. An important theoretical foundation for LAP is the Speech Act Theory (Austin, 1962; Habermas, 1984; Searle, 1969). Uttering a sentence is the performance of a purposeful act, a so-called speech act. LAP emphasizes the need for regarding the performance of business processes as patterns of inter-related speech acts (Flores \& Ludlow, 1980). Winograd \& Flores (Winograd \& Flores, 1986) extend this idea and introduce a conversation-for-action schema, which covers a number of state changes, e.g., someone (A) states a request, someone else (B) makes a promise and then reports completion, which in the end A declares completed.

Several frameworks have been developed based on the language-action perspective, such as a layered pattern approach for electronic commerce transaction (Weigand, Heuvel, \& Dignum, 1998), generic layered patterns for business modeling (Lind \& Goldkuhl, 2001) and an aggregative atoms, molecules and matter model (Dietz, 2002). Other approaches include Action Workflow (Medina-Mora et al., 1992), Dynamic Essential Modelling (DEMO) (Dietz, 1994, 2001; Reijswoud, Mulder, \& Dietz, 1999), and Business Action Theory (BAT) (Goldkuhl, 1996, 1998; Lind \& Goldkuhl, 1997, 2001). These efforts, which have built a layered view of 
communication-oriented business activities, provide further support to the argument that LAP can provide the basis for understanding the web services standards space.

\subsection{An LAP-inspired framework for the web services standards space}

Developing an LAP-inspired framework for the web services standards space requires one key adaptation of the premises underlying LAP. The participants in the communicative action represent computationally described web services instead of organizational actors (Aakhus, 2004). As established in the previous section, the objective remains carrying out specific business activities. Following LAP, this can be achieved if (a) there is a common platform through which participants can share, exchange and reach common understanding on assumptions, values and norms of their interaction; (b) participants can advertise, negotiate and reach mutual commitments for performing purposive business activities; and (c) participants engage in rational discourse to perform their committed business actions and resolve any breakdowns that may occur during their interaction (Klein \& Huynh, 2004). The framework we propose, accordingly, consists of three levels: (a) communication platform, (b) communicative act, and (c) rational discourse.

\section{Communication platform}

The first level is the enabler of communicative acts between communicating parties. In LAP, the process of performing a communicative act is a social action (Goldkuhl \& Agerfalk, 2000; Searle, 1969). In order to make a communicative act successful, four conditions are required (Dietz, 2001, 2004):

- There must be a communication channel, i.e., there should be a transportation protocol to transport communicative messages between parties.

- There must be a common syntax, so that messages are correctly recognized by the parties.

- There must be common semantics, so that messages are correctly interpreted by the parties. 
- There must be common social culture between parties, so that they have full agreement on the commitments raised by the communicative acts.

The above conditions suggest that a prerequisite to successful communicative acts is a communication platform. It can be divided into three layers: [channel], [messaging] and [guarantee]. The first condition establishes the need for a communication channel between parties as a conduit of messages. The second and third conditions establish the need for common syntax and semantics for messages. The fourth condition guarantees that the expectations for interpretation of messages are shared by the communicating parties.

\section{Communicative act}

The second level creates commitments between communicating parties (Dietz, 2001) for some future action (Searle, 1969) and creates a "shared understanding” against a shared background (Habermas, 1984). The participants achieve this goal through four phases (Goldkuhl, 1996, 1998):

- First, the participant who has ability (capacity and know-how) to perform an action offers and exposes it in a form searchable by other participants.

- Second, a participant who needs certain performance of an action, searches for partners who offer this ability.

- Third, after the participants find each other, they establish contact, exchange proposals and negotiate with each other to reach an agreement (Schoop, 2002).

- Finally, the participants establish a formal contract which expresses mutual commitments of the participants for future actions.

The four phases directly map to four layers: [capability exposure], [capability search], [proposal and negotiation] and [contract establishment].

\section{Rational discourse}

The third level emerges out of the performance of patterns of communicative acts (Auramaki et al., 1988; Klein \& Huynh, 2004; Lyytinen, Lehitnen, \& Auramäki, 1987). Rational discourse occurs among actors, when they pursue their own goals and harmonize their plans of 
action based on a common definition of the situation (Cecez-Kecmanovic \& Janson, 1999;

Reijswoud et al., 1999). This coordination via rational discourse can include four layers:

- First, interaction between actors consist of patterns of triggers and responses (Dietz, 2002; Lind \& Goldkuhl, 2001), i.e., conversations among actors are made up of a finite sequence of communicative acts (Dietz, 2002; Weigand et al., 1998).

- Second, a composition of related exchanges can lead to a goal state that is satisfactory to the needs of the actors (Dietz, 2002; Lind \& Goldkuhl, 2001). Each exchange, thus, represents a step that facilitates transition from an initial state to a goal state (Klein \& Huynh, 2004; Lind \& Goldkuhl, 2001).

- Third, recurring or long-term transactions require establishing relationships among actors, and sustaining or improving them over time (Lind \& Goldkuhl, 2001).

- Finally, concurrent contracts may be run with several parties (Weigand et al., 1998). This includes the need to regulate long term contracts, and the ability to change business transactions as the contracts changes (Goldkuhl \& Melin, 2001), i.e., it requires a global overview of running contracts and explicit control of the running transactions and existing relationships (Weigand et al., 1998).

These map to the four layers: [exchange], [transaction], [relationship management] and [managing concurrent contracts] respectively.

Table 1 outlines the LAP-inspired framework. The first level (at the bottom of the table), communication platform, describes 'how' communicative acts are enabled; the second level (in the middle of the table), communicative act, focuses on 'what' the acts themselves constitute; and the third level (at the top of the table), rational discourse, emphasizes 'why' patterns of communicative acts are carried out, e.g., to achieve business goals.

The next section demonstrates how the proposed 'reference framework' can be used to assess existing web services standards stacks. 
Table 1. An LAP-inspired framework for the web services standards space

Rational discourse (coordination among actors based on commitments for achieving business goals)

\begin{tabular}{|l|l} 
[Managing concurrent & Managing concurrent contracts, i.e., managing contracts with multiple partners, “
\end{tabular}

contracts] (Weigand et al., $\quad$ interactions between several contracts that run concurrent between several 1998)

parties.” (Weigand et al., 1998), "a global overview, a representation of the contracts” (Weigand et al., 1998).

[Relationship management]

(similar to transaction group

(Lind \& Goldkuhl, 2001),

contract (Weigand et al., 1998))

[Transaction] (similar to business transactions (Lind

\& Goldkuhl, 2001), business

process (Dietz, 2002),

workflow (Weigand et al., 1998), contract (Weigand et al., 1998))

[Exchange] (Exchange in

(Lind \& Goldkuhl, 2001),

includes Action pair (Lind

\& Goldkuhl, 2001), similar

to interaction (Dietz, 2002),

similar to transaction

(Weigand et al., 1998))

Relationship management deals with multiple or recurring transactions with one partner following a long term contract, "The recurrent business transactions need to be framed within a wider agreement. .. (Lind \& Goldkuhl, 2001), “... creation and sustainment of business relations"” (Weigand et al., 1998)

A pattern built from different types of exchanges related to each other

(composition of interrelated activities or interactions to achieve a goal)

“..composition of connected interactions.” (Dietz, 2002), “... transaction includes

a number of different exchanges, where each of these exchanges constitutes the ... transaction’s different phases.” (Lind \& Goldkuhl, 2001), “..a set of related transactions aimed at some goal.” (Weigand et al., 1998)

A exchange involves interaction between actors consisting of patterns of trigger and response, "patterns of triggers and responses.” (Lind \& Goldkuhl, 2001), "An exchange means that one actor gives something in return for something given by another actor.” (Lind \& Goldkuhl, 2001), “ ... acts appear to occur in particular patterns. ..... we call these patterns conversations. (Dietz, 2002), "the smallest possible sequence of actions (speech acts) that leads to a certain...state" (Weigand et al., 1998)

Communicative act (creating commitments between communicating parties)

[Contract establishment] (Goldkuhl, 1996, 1998;

Habermas, 1984; Lind \& Provider and customer enter into commitments to perform a business transaction. "Customer and supplier come to an agreement concerning the business

Goldkuhl, 1997)

[Proposal and negotiation] (Goldkuhl, 1996, 1998; Habermas, 1984; Schoop, 2002) transaction. The contract is a mutual communicative action expressing the mutual commitments made; i.e., commitments for future actions." (Goldkuhl, 1998)

Participants negotiate with each other through interpretation of the situation at hand and seek to achieve consensus. "Bids and counter-bids are made. The desire and demand of the customer are expressed. The supplier can make different offers.” (Goldkuhl, 1998), “.. characterized by highly dynamic and interactive exchanges that can range from simple orders from a product catalogue to complex negotiations involving offers, counter-offers, bargaining etc.” (Schoop, 2002).

[Capability search] (Goldkuhl, 1996, 1998; Habermas, 1984; Lind \& Goldkuhl, 1997) [Capability exposure] (Goldkuhl, 1996, 1998; Habermas, 1984; Lind \& Goldkuhl, 1997; Reijswoud \& Lind, 1998) Customers desiring a capability seek contact with providers providing the capability. "The customer does not have the corresponding ability ... needs which may be satisfied by potential suppliers and their products (goods/services)"'(Goldkuhl, 1998). Participants offer and exposes their business in a form searchable by other participants, "ability is offered and exposed to the market" (Reijswoud \& Lind, 1998), "The supplier must have an ability (a capacity and a know-how) to perform business; to make offers and contracts and to fulfill these contracts." (Goldkuhl, 1998)

Communication platform (preconditions to make communicative acts successful)

[Guarantee] (Dietz, 2001; Habermas, 1984) Ensuring delivery without distortion, "free from any kind of distortion, any form of coercion and ideology "that excludes all force...except the force of the better argument." (Habermas, 1984).

[Messaging] (Dietz, 2001; Habermas, 1984) Common syntax and semantics, "The concept of communicative action presupposes the use of language as a medium for a kind of reaching understanding...” (Habermas, 1984)

$\begin{array}{ll}\text { [Channel] (Dietz, 2001) } & \text { Conduit to carry messages }\end{array}$

Legend (followed throughout the remainder of the paper): Level [Layer within a level] 


\section{Assessment of existing web services standards stacks}

\subsection{Assessment of the W3C initiative}

Table 2 summarizes the results of assessing the W3C initiative (WS Arch, 2005) against the LAP-inspired reference framework.

Table 2. Assessing the W3C initiative against the LAP-inspired framework

\begin{tabular}{|c|c|c|}
\hline LAP-inspired framework & $\begin{array}{l}\text { Corresponding layer in W3C } \\
\text { initiative (WS Arch, 2005) }\end{array}$ & $\begin{array}{l}\text { Standards proposed (see } \\
\text { Appendix A) }\end{array}$ \\
\hline \multicolumn{3}{|l|}{ Rational discourse } \\
\hline [Managing concurrent contracts] & Management & MUWS and MOWS \\
\hline [Relationship management] & None & \\
\hline [Transaction] & Aggregation & WS-BPEL \\
\hline [Exchange] & Choreography & WS-CDL, WS-CF, WS-TXM \\
\hline \multicolumn{3}{|l|}{ Communicative act } \\
\hline [Contract establishment] & None & \\
\hline [Proposal and negotiation] & None & \\
\hline [Capability search] & Discovery & UDDI \\
\hline [Capability exposure] & Description & WSDL \\
\hline \multicolumn{3}{|l|}{ Communication platform } \\
\hline [Guarantee] & Messaging Extensions & $\begin{array}{l}\text { WS-Security, WS-Addressing, WS- } \\
\text { Reliability }\end{array}$ \\
\hline [Messaging] & Messaging & SOAP \\
\hline [Channel] & Communications & HTTP, FTP \\
\hline
\end{tabular}

The communication platform layers demonstrate the clearest mapping between the LAPinspired framework and the W3C initiative. The communications layer outlines the requirements for communication between services similar to the [channel] layer in the LAP-inspired framework. Key standards in this layer include HTTP (HTTP, 1999) and FTP (FTP, 1985). The messaging layer facilitates communication between services by providing them a flexible and extensible mechanism for exchanging messages (Gottschalk, Graham, Kreger, \& Snell, 2002; Kreger, 2003). It specifies a common syntax necessary for formulating messages. This layer, thus, corresponds to the [messaging] layer in the LAP-inspired framework. Messaging extensions include security, addressing and reliability, which correspond to the notion of providing guarantees that ensure communication without distortions. This layer, thus, corresponds to the [guarantee] layer in the LAP-inspired framework. Some of the available standards in the 
Messaging and Messaging extensions layers include SOAP (SOAP, 2003) and extensions such as WS-Security (WS-Security, 2004), WS-Addressing (WS-Addressing, 2005) and WS-Reliability (WS-Reliability, 2004).

The communicative act layers demonstrate the least mapping between the LAP-inspired framework and the W3C initiative. The description layer provides a functional description of a service in terms of its interface and implementation (Turner et al., 2003); (Kreger, 2003). This layer, thus, corresponds to the [capability exposure] layer in the LAP-inspired framework. The key standard in this layer is the WSDL (WSDL, 2001). The discovery layer specifies mechanisms for discovering a service, i.e., locating a machine-readable description of a service (WS Arch, 2005). This layer, thus, allows service providers to publish their services descriptions to a business registry, so that service requestors can search and discover services that meet their requirements. This layer, thus, corresponds to the [capability search] layer in the LAP-inspired framework. The standard available in this layer is UDDI (UDDI, 2005). Layers from the LAP-inspired framework with no corresponding efforts in the W3C initiative, therefore, include [proposal and negotiation], and [contract establishment].

Finally, the rational discourse layers also demonstrate significant mapping between the LAP-inspired framework and the W3C initiative. The choreography layer defines the sequence and conditions under which messages are exchanged among services in order to achieve a goal state (WS Arch, 2005). This layer, thus, corresponds to the [exchange] layer in the LAP-inspired framework. Available standards in this layer include WS-CDL (WS-CDL, 2004), WS-CF (WSCF, 2004), and WS-TXM (WS-TXM, 2003). Second, the notion of aggregation in the stack proposed by the W3C initiative refers to the composition of web services (including any interaction and message flows between them (WS Arch, 2005)) and their representation as a 
higher-level web service (Gottschalk et al., 2002). This directly corresponds to the [transaction] layer in the LAP-inspired framework. Existing standards in this layer include WS-BPEL (WSBPEL, 2005). Finally, the management layer provides a mechanism to monitor and control the execution of web services. It defines the model for managing web services as a resource. This corresponds to the [managing concurrent contracts] layer in the LAP-inspired framework. Standards in this layer include MUWS (WSDM, 2005) and MOWS (WSDM, 2005). Layers from the LAPinspired framework with no corresponding efforts in the W3C initiative, therefore, include [relationship management]. The next two sub-sections assess the other two initiatives. The discussion that follows is not as comprehensive as that in section 4.1 to reduce redundancy.

\subsection{Assessment of the semantic web services initiative}

The semantic web services initiative provides a framework based on a set of roles and requirements for machine-readable semantic descriptions for deployment of web services (SWS Arch, 2005). Table 3 summarizes the results of assessing the semantic web services initiative against the LAP-inspired framework.

The communication platform layers demonstrate the clearest mapping between the LAPinspired framework and the semantic web services initiative because they utilize the foundation provided by the W3C initiative, enhancing it with the Ontology Web Language (OWL, 2004).

The communicative act layers also demonstrate significant mapping between the LAPinspired framework and the semantic web services initiative. First, the published advertisement and service model layer provides protocols that service providers can use to advertise their services (SWS Arch, 2005) corresponding to the [capability exposure] layer in the LAP-inspired framework. Next, the client characterization of service provider sub-layer provides clients the ability to formulate abstract descriptions of requirements that candidate services must meet 
(SWS Arch, 2005). The service discovery query process sub-layer provides a protocol that a broker service can use to respond to client queries (SWS Arch, 2005). Together, these two sublayers correspond to the [capability search] layer in the LAP-inspired framework. The next layer, client characterization of desired activity, provides the means to exchange information about goals and capabilities of parties involved in the communicative act (SWS Arch, 2005). This layer corresponds to the [proposal and negotiation] layer in the LAP-inspired framework. The next layer, service contract negotiation, provides a protocol that service providers and clients can use to negotiate and establish contracts (SWS Arch, 2005). This layer corresponds to the [contract establishment] layer in the LAP-inspired framework. The standard that crosses all these layers is SWSL-Rules (SWSL, 2005).

Table 3. Assessing the Semantic Web Services-initiative against the LAP-inspired framework

\begin{tabular}{|c|c|c|}
\hline $\begin{array}{l}\text { LAP-inspired } \\
\text { framework }\end{array}$ & $\begin{array}{l}\text { Corresponding layer in the Semantic } \\
\text { Web Services initiative (SWS Arch, 2005) }\end{array}$ & $\begin{array}{l}\text { Standards proposed (see } \\
\text { Appendix A) }\end{array}$ \\
\hline \multicolumn{3}{|l|}{ Rational discourse } \\
\hline $\begin{array}{l}\text { [Managing concurrent } \\
\text { contracts] }\end{array}$ & $\begin{array}{l}\text { Status monitoring; termination and } \\
\text { compensation }\end{array}$ & SWSL-FOL \\
\hline $\begin{array}{l}\text { [Relationship } \\
\text { management] }\end{array}$ & None & \\
\hline [Transaction] & $\begin{array}{l}\text { Contact initiation; status monitoring; } \\
\text { termination and compensation }\end{array}$ & SWSL-FOL, OWL-S \\
\hline [Exchange] & None & \\
\hline \multicolumn{3}{|l|}{ Communicative act } \\
\hline [Contract establishment] & Service contract negotiation & \multirow{3}{*}{ SWSL-Rules } \\
\hline [Proposal and negotiation] & $\begin{array}{l}\text { Client characterization of desired activity; } \\
\text { Service contract negotiation }\end{array}$ & \\
\hline [Capability search] & $\begin{array}{l}\text { Client characterization of service providers; } \\
\text { service discovery process }\end{array}$ & \\
\hline [Capability exposure] & Published advertisement and service model & OWL-S, WSDL, SWSL-Rules \\
\hline \multicolumn{3}{|l|}{ Communication platform } \\
\hline [Guarantee] & \multirow{3}{*}{$\begin{array}{l}\text { Uses the W3C initiative: [channel], messaging } \\
\text { and messaging extensions, enhanced by } \\
\text { Ontology Web Language (OWL). }\end{array}$} & $\begin{array}{l}\text { WS-Security, WS-Addressing, } \\
\text { WS-Reliability }\end{array}$ \\
\hline [Messaging] & & SOAP, OWL \\
\hline [Channel] & & HTTP, FTP \\
\hline
\end{tabular}

The rational discourse layers demonstrate the least mapping between the LAP-inspired framework and the semantic web services initiative. First, the contract initiation sub-layer provides a protocol for clients to invoke the selected service. Next, the status monitoring sub- 
layer facilitates monitoring service execution, including mechanisms for stopping, resuming or restarting the service. The termination and compensation sub-layer provides a protocol for indicating success or failure. Together these three sub-layers correspond to the [transaction] layer in the LAP-inspired framework. The status monitoring and termination and compensation sublayers also contain elements that correspond to the [managing concurrent contracts] layer in the LAP-inspired framework. Standards available for these layers include OWL-S and SWSL-FOL (SWSL, 2005). Layers from the LAP-inspired framework with no corresponding efforts in the semantic web services initiative, therefore, include [exchange] and [relationship management].

\subsection{Assessment of the ebXML initiative}

The ebXML initiative combines components from divergent XML initiatives to develop a single business standard (ebXML-Req, 2001) that can operate on existing EDI implementations (ebXML-TA, 2001). Table 4 summarizes the results of assessing the ebXML initiative against the LAP-inspired framework.

Table 4. Assessing the ebXML-based initiative against the LAP-inspired framework

\begin{tabular}{|c|c|c|}
\hline LAP-inspired framework & $\begin{array}{l}\text { Corresponding layer in the ebXML } \\
\text { based initiative (ebXML-TA, 2001) }\end{array}$ & $\begin{array}{l}\text { Standards proposed (see } \\
\text { Appendix A) }\end{array}$ \\
\hline \multicolumn{3}{|l|}{ Rational discourse } \\
\hline [Managing concurrent contracts] & None & \\
\hline [Relationship management] & None & \\
\hline [Transaction] & Business process and information modeling & BPIM \\
\hline [Exchange] & Business process specification schema & BPSS \\
\hline \multicolumn{3}{|l|}{ Communicative act } \\
\hline [Contract establishment] & Collaborative protocol agreement & CPA \\
\hline [Proposal and negotiation] & None & \\
\hline [Capability search] & Registry & ebXML RS, ebXML RIM \\
\hline [Capability exposure] & Collaborative protocol profile & $\mathrm{CPP}$ \\
\hline \multicolumn{3}{|l|}{ Communication platform } \\
\hline [Guarantee] & \multirow{2}{*}{ Messaging service } & \multirow{2}{*}{ SOAP, ebXML MS } \\
\hline [Messaging] & & \\
\hline [Channel] & Communication protocol & HTTP, FTP \\
\hline
\end{tabular}

The communication platform layers show a clear mapping between the LAP-inspired framework and the ebXML initiative. First, the communication protocol layer utilizes standards 
such as HTTP and FTP for sending and receiving messages. This layer, therefore, corresponds to the [channel] layer in the LAP-inspired framework. Next, the messaging service layer provides the mechanism for sending ebXML messages over SOAP (ebMS, 2002). This layer, therefore, corresponds to the [Messaging] and [Guarantee] layers in the LAP-inspired framework.

The communicative act layers also show a significant mapping against the LAP-inspired framework. First, the collaboration protocol profile layer describes partner capabilities and service interface requirements (ebXML-TA, 2001). This layer contains CPP (ebXML-CPPA, 2002) as the key standard, and, therefore, corresponds to the [capability exposure] layer in the LAP-inspired framework. Second, the registry layer facilitates information sharing between parties by providing a centralized repository (ebRS, 2002). It includes two elements: a registry service (interface for accessing the registry including interaction protocols, message definitions and schemas) (ebRS, 2002) and a registry information model (types of metadata of documents that are stored in the registry including relationships among the various metadata classes) (ebRIM, 2002). These elements correspond to the [capability search] layer in the LAP-inspired framework. The key standards in this layer include ebXML RS (ebRS, 2002) and ebXML RIM (ebRIM, 2002). Third, the collaboration protocol agreement layer describes the agreement between partners about their respective commitments and expectations (ebXML-CPPA, 2002; Ibbotson, 2001). The key standard in this layer is CPA (ebXML-CPPA, 2002). This layer corresponds to the [contract establishment] layer in the LAP-inspired framework. One layer from the LAP-inspired framework with no corresponding effort in the ebXML initiative, therefore, is [proposal and negotiation].

The rational discourse layers demonstrate the least mapping against the LAP-inspired framework. First, the business specification schema layer (ebBPSS, 2001) provides a nominal set 
of elements necessary to specify collaboration between business partners (Rawlins, 2002). This layer corresponds to the [exchange] layer in the LAP-inspired framework. The key standard in this layer is BPSS (ebBPSS, 2001). Next, the business process and information modeling layer provides mechanisms for trading parties to capture specific details of a business scenario and model a business process using a consistent modeling methodology (eBPOver, 2001). This layer corresponds to the [transaction] layer in the LAP-inspired framework. The key standard in this layer is BPIM (eBPOver, 2001). Layers from the LAP-inspired framework with no corresponding efforts in the ebXML initiative, therefore, include [relationship management] and [managing concurrent contracts].

\section{Discussion}

The assessment of the three web services initiatives reported in the previous section suggests several recurring themes. As expected, the communication platform level appears to be common across the three standardization efforts, and shows the clearest mapping against the LAP-inspired framework. In particular, it shows clear agreement on the [channel] layer. This further translates to all three initiatives relying on standards recommended by the W3C. The agreement is also significant for the [messaging] layer (i.e., SOAP). The semantic web services initiative augment these basic standards by including OWL and the ebXML initiative augments these with additional syntax and delivery mechanisms. While no agreement has been reached yet on the [guarantee] layer (instantiated, for example, by the W3C initiative as WS-security and WSreliability), adherence to common W3C standards on the lower layers suggests such agreement is a likely outcome in the near future.

At the communicative act level, all three initiatives provide standards for the [capability exposure] layer, although with slight variations. All three initiatives also provide standards for the 
[capability search] layer. The semantic web services initiative expands this to include the ability to specify desired characteristics of service providers. The semantic web services initiative is also the only initiative to provide standards for the [proposal and negotiation] layer. The W3C and ebXML initiatives indicate no standards for this layer, proposed or recommended. Useful directions for creating standards in this layer are available elsewhere (Jertila \& Schoop, 2005; Schoop, 2003). Finally, the W3C initiative is the only initiative that does not provide any standards for the [contract establishment] layer.

At the rational discourse level, the W3C initiative efforts are better developed than the semantic web services and ebXML initiatives. For the [exchange] layer, the W3C and ebXML initiatives provide competing, though well-developed alternatives. All three initiatives contain standards that provide partial support for the [transaction] layer. However, none provides protocols for conversation policies that can guide interaction between services including mechanisms to handle any exceptions. Useful research in this direction is available elsewhere, which can be leveraged for creation or refinement of standards (Fan, Umapathy, Yen, \& Purao, 2004; Kimbrough \& Yang, 2004; Moore, 2000, 2001; Umapathy, Purao, \& Sugumaran, 2003).

None of the initiatives propose standards for managing relationships established through a contract or provide the ability to extend contracts over a long-term. As business transactions cross national and cultural boundaries, [relationship management] is an important aspect that can benefit from formalized approaches. This is a significant drawback for all three initiatives. Useful research in this direction is available elsewhere (Goldkuhl \& Melin, 2001; Goldkuhl \& Röstlinger, 1999). Finally, there is minimal support for the uppermost layer, [managing concurrent contracts]. The standards proposed by the W3C and semantic web services initiatives manage only a single contract or transactions related to that single contract, i.e., they do not provide a 
global overview of multiple contracts and their related multiple transactions as suggested by the LAP-inspired framework. Table 5 summarizes the above observations and provides pointers to additional research that may be useful for refinement of current standards.

Table 5: Assessment of the three standards initiatives against the LAP-inspired framework

\begin{tabular}{|c|c|c|c|c|}
\hline \multirow[b]{2}{*}{$\begin{array}{l}\text { LAP-inspired } \\
\text { Framework }\end{array}$} & \multicolumn{3}{|c|}{ Current Initiatives } & \multirow[b]{2}{*}{ Comments } \\
\hline & W3C & $\begin{array}{l}\text { Semantic } \\
\text { web }\end{array}$ & ebXML & \\
\hline \multicolumn{5}{|l|}{ Rational discourse } \\
\hline $\begin{array}{l}\text { [Managing concurrent } \\
\text { contracts] }\end{array}$ & Partic & support & No support & $\begin{array}{l}\text { W3C and the semantic web services initiatives do } \\
\text { not support management of concurrent contracts } \\
\text { spanning multiple relationships and transactions }\end{array}$ \\
\hline $\begin{array}{l}\text { [Relationship } \\
\text { management] }\end{array}$ & \multicolumn{3}{|c|}{ No support } & $\begin{array}{l}\text { Needs mechanisms to create } \\
\text { relationships (see (Goldkuhl \& } \\
\text { Goldkuhl \& Röstlinger, 1999)). }\end{array}$ \\
\hline [Transaction] & \multicolumn{3}{|c|}{ Partial support } & $\begin{array}{l}\text { Needs mechanisms to support long running multi- } \\
\text { party conversations (see (Fan et al., 2004; } \\
\text { Kimbrough \& Yang, 2004; Moore, 2000, 2001; } \\
\text { Umapathy et al., 2003)). }\end{array}$ \\
\hline [Exchange] & $\begin{array}{c}\text { Full } \\
\text { support }\end{array}$ & No support & $\begin{array}{c}\text { Full } \\
\text { support }\end{array}$ & $\begin{array}{l}\text { No separate standard in the semantic web services } \\
\text { initiative }\end{array}$ \\
\hline \multicolumn{5}{|l|}{ Communicative act } \\
\hline [Contract establishment] & $\begin{array}{c}\text { No } \\
\text { support }\end{array}$ & \multicolumn{2}{|c|}{ Full support } & $\begin{array}{l}\text { W3C initiative needs mechanisms to create binding } \\
\text { commitments on participants. }\end{array}$ \\
\hline $\begin{array}{l}\text { [Proposal and } \\
\text { negotiation] }\end{array}$ & $\begin{array}{c}\text { No } \\
\text { support }\end{array}$ & $\begin{array}{c}\text { Partial } \\
\text { support }\end{array}$ & No support & $\begin{array}{l}\text { Needs mechanisms for complex negotiations (see } \\
\text { (Jertila \& Schoop, 2005; Schoop, 2003)). }\end{array}$ \\
\hline [Capability search] & $\begin{array}{l}\text { Partial } \\
\text { support }\end{array}$ & $\begin{array}{l}\text { Full } \\
\text { support }\end{array}$ & $\begin{array}{l}\text { Partial } \\
\text { support }\end{array}$ & $\begin{array}{l}\text { W3C and ebXML initiatives do not provide the } \\
\text { ability for service requestors to describe desired } \\
\text { provider characteristics. }\end{array}$ \\
\hline [Capability exposure] & \multicolumn{3}{|c|}{ Full support } & \\
\hline \multicolumn{5}{|l|}{ Communication platform } \\
\hline [Guarantee] & $\begin{array}{c}\text { Full } \\
\text { support }\end{array}$ & \multicolumn{2}{|c|}{ No support } & $\begin{array}{l}\text { Possible that W3C standards may be adapted by the } \\
\text { other initiatives. }\end{array}$ \\
\hline [Messaging] & \multicolumn{3}{|c|}{ Full support } & \\
\hline [Channel] & \multicolumn{3}{|c|}{ Full support } & \\
\hline
\end{tabular}

One additional observation follows from the assessment of the three initiatives against the LAP-inspired framework. The framework suggests crisp boundaries built on the notion of "layers" as emphasized in prior work in the LAP research stream. This is apparent in the writings of Weigand (Weigand et al., 1998), Goldkuhl (Lind \& Goldkuhl, 2001) and Dietz (Dietz, 2002) among others. Each has implicitly argued that the phenomenon (communicative action among actors in an organization) is complex, and needs to be unpacked into several layers to understand this complexity. This is particularly true for web services, where the standards should be carved 
into crisp components in order to ensure interoperability. Such crisp boundaries are not evident in many of the standards being developed negating the benefits of 'separation of concerns' known in the computing community. For example, the semantic web services initiative uses SWSL-Rules as a standard that spans as many as four layers (see Table 3). Similar outcomes are seen for the ebXML initiative, with standards spanning multiple layers in the communication platform (see Table 4). The W3C initiative appears to do well in this regard, perhaps due to the presence of multiple strong market participants, who may be implicitly enforcing the boundaries across layers as a way of ensuring separation of concerns.

We believe that the development and refinement of standards in a domain as important as web services should be guided by theoretical considerations. We hope that the analyses and assessment we have reported here, following the LAP theories, can suggest useful guidelines and constraints for these emerging standards. Our future work focuses on discovering foundational constructs that underlie LAP theories to provide insights into specific functionalities of web services standards.

\section{References}

1. Aakhus, M. (2004). Felicity conditions and genre: Linking act and conversation in LAP style conversation analysis. Paper presented at the International Working Conference on the LanguageAction Perspective on Communication Modelling.

2. Ankolekar, A., Burstein, M., Hobbs, J. R., et al. (2001). DAML-S: Semantic Markup For Web Services. International Semantic Web Workshop.

3. Auramaki, E., Lehtinen, E., \& Lyytinen, K. (1988). A Speech-Act-based Office Modeling Approach. ACM Transactions on Information Systems (TOIS), 6(2), 126-152.

4. Austin, J. L. (1962). How to do Things with Words: Oxford.

5. Brodie, M. L., Mylopoulos, J., \& Schmidt, J. W. (1984). On Conceptual Modelling. Perspectives from Artificial Intelligence, Databases, and Programming Languages. New York: Springer-Verlag.

6. Cecez-Kecmanovic, D., \& Janson, M. (1999). Communicative Action Theory: An Approach to Understanding the Application of Information Systems. Paper presented at the Australasian Conference on Information Systems, Wellington, New Zealand. 
7. Curbera, F., Khalaf, R., Mukhi, N., et al. (2003). The next step in Web services. Communications of the ACM, 46(10), 29-34.

8. De Michelis, G., \& Grasso, M. (1994). Situating Conversations within the Language/Action Perspective: The Milan Conversation Model. Paper presented at the Conference on Computer Supported Cooperative Work.

9. Dietz, J. L. G. (1994). Business Modeling for Business Redesign. Paper presented at the Hawaii International Conference on System Sciences (HICSS), Maui, Hawaii.

10. Dietz, J. L. G. (2001). Coherent, Consistent and Comprehensive Modeling of Communication, Information, Action and Organzation. In Information Modeling in the New Milennium (pp. 9-33): Idea Group Publishing.

11. Dietz, J. L. G. (2002). The Atoms, Molecules and Matter of Organizations. Paper presented at the International Working Conference on the Language-Action Perspective on Communication Modelling (LAP).

12. Dietz, J. L. G. (2004, June 2-3). Towards a LAP-based Information Paradigm. Paper presented at the International Working Conference on the Language-Action Perspective on Communication Modelling (LAP), Rutgers University, New Brunswick, NJ, USA.

13. ebBPSS. (2001, 11 May 2001). Business Process Specification Schema. Retrieved March 08, 2005, from http://www.ebxml.org/specs/ebBPSS_print.pdf

14. eBPOver. (2001, 11 May 2001). Business Process and Business Information Analysis Overview. Retrieved March 08, 2005, from http://ebxml.org/specs/bpOVER_print.pdf

15. ebRIM. (2002, April 2002). OASIS/ebXML Registry Information Model. Retrieved March 7, 2005, from http://www.oasis-open.org/committees/regrep/documents/2.0/specs/ebrim.pdf

16. ebRS. (2002, April 2002). OASIS/ebXML Registry Services Specification. Retrieved March 7, 2005, from http://www.oasis-open.org/committees/regrep/documents/2.0/specs/ebrs.pdf

17. ebXML. (2005). About ebXML. Retrieved February 2005, 2005, from http://www.ebxml.org/geninfo.htm

18. ebXML Glossary. (2001). ebXML Glossary. Retrieved October 31, 2005, from http://www.ebxml.org/specs/ebGLOSS_print.pdf

19. ebXML-CPPA. (2002, September 23, 2002). Collaboration-Protocol Profile and Agreement Specification. Retrieved March 07, 2005, from http://www.ebxml.org/specs/ebcpp-2.0.pdf

20. ebXML-Req. (2001). ebXML Requirements Specification. Retrieved February 19, 2005, from http://www.ebxml.org/specs/ebREQ.pdf

21. ebXML-TA. (2001, 16 February 2001). ebXML Technical Architecture Specification v1.0.4. Retrieved February 19, 2005, from http://ebxml.org/specs/ebTA.pdf

22. Fan, X., Umapathy, K., Yen, J., et al. (2004, 2004/01//). An Agent-Based Approach for Interleaved Composition and Execution of Web Services. Paper presented at the International Conference on Conceptual Modeling (ER), Shanghai, China.

23. Flores, F., \& Ludlow, J. (1980). Doing and Speaking in the Office. In G. Fick \& R. H. Sprague (Eds.), Decision Support Systems: Issues and Challenges (Vol. 11, pp. 95-118). New York: Pergamon Press.

24. FTP. (1985). File Transfer Protocol (FTP). Retrieved June 7, 2005, from http://www.w3.org/Protocols/rfc959/ 
25. Goldkuhl, G. (1996). Generic Business Frameworks and Action Modelling. Paper presented at the International Working Conference on the Language-Action Perspective on Communication Modelling (LAP).

26. Goldkuhl, G. (1998). The Six Phases of Business Processes - Business Communication and the Exchange of Value. Paper presented at the International Telecommunications Society (ITS) Conference - Beyond Convergence: Communication into the Next Millennium, Stockholm, Sweden.

27. Goldkuhl, G., \& Agerfalk, P. J. (2000). Actability: A way to understand information systems pragmatics. Paper presented at the International Workshop on organisational semiotics, Staffordshire University.

28. Goldkuhl, G., \& Lyytinen, K. (1982). A Language Action View of Information Systems. International Conference on Information Systems.

29. Goldkuhl, G., \& Lyytinen, K. (1984). Information System Specification as Rule Reconstruction. In T. A. Bemelmans (Ed.), Beyond Productivity - Information Systems for Organizational Effectiveness (pp. 79-95). New York: North-Holland: Proceedings of IFIP WG 8.2.

30. Goldkuhl, G., \& Melin, U. (2001). Relationship management vs business transactions: Business interaction as design of business interaction. Paper presented at the International Purchasing and Supply Education and Research Association (IPSERA).

31. Goldkuhl, G., \& Röstlinger, A. (1999, September 12-13). Expanding the Scope - From Language Action to Generic Practice. Paper presented at the International Working Conference on the Language-Action Perspective on Communication Modelling (LAP), Copenhagen.

32. Gosain, S. (2003). Realizing The Vision for Web Services: Strategies for Dealing With Imperfect Standards. Paper presented at the MIS Quartely Special Issue Workshop on: Standard Making - A Critical Research Frontier for Information Systems.

33. Gottschalk, K., Graham, S., Kreger, H., et al. (2002). Introduction to Web services architecture. IBM Systems Journal, 41(2), 170-177.

34. Habermas, J. (1984). The Theory of Communicative Action: Reason and the Rationalization of Society (T. McCarthy, Trans. Vol. 1). Boston: Beacon Press.

35. Hirschheim, R., Klein, H., \& Lyytinen, K. (1995). Information Systems Development and Data Modeling, Conceptual and Philosophical Foundations: Cambridge University Press.

36. Holmström, J., \& Truex, D. (2001). What does it mean to be an informed IS researcher? Some criteria for the selection and use of social theories in IS research. Information Systems Research Seminar in Scandinavia (IRIS), 313-326.

37. HTTP. (1999). Hypertext Transfer Protocol -- HTTP/1.1. Retrieved June 7, 2005, from http://www.w3.org/Protocols/rfc2616/rfc2616.html

38. Ibbotson, J. (2001). ebXML Trading-Partners Specification. Paper presented at the XML Europe, Internationales Congress Centrum (ICC), Berlin, Germany.

39. Jertila, A., \& Schoop, M. (2005). The Language-Action Perspective and the Semantic Web-A Language-Action Approach to Electronic Contracts. Paper presented at the International Working Conference on the Language-Action Perspective on Communication Modelling (LAP), Kiruna, Sweden.

40. Kimbrough, S. O., \& Yang, Y. (2004). Action at the Tables: Sketching a Tabular Representation for Utterances under the Language-Action Perspective. Paper presented at the International Working Conference on the Language-Action Perspective on Communication Modelling (LAP). 
41. Klein, H. K., \& Huynh, M. Q. (2004). The Critical Social Theory of Jürgen Habermas and its Implications for IS Research. In J. Mingers \& L. Willcocks (Eds.), Social Theory and Philosophy for Information Systems (pp. 157 - 237). West Sussex, England: John Wiley and Sons Ltd.

42. Kreger, H. (2001, May 2001). Web Services Conceptual Architecture (WSCA 1.0). Retrieved June 6, 2005, from http://www-306.ibm.com/software/solutions/webservices/pdf/WSCA.pdf

43. Kreger, H. (2003). Fulfilling the Web services promise. Communications of the ACM, 46(6), 29-34.

44. Lemniotes, T., Papadopoulos, G. A., \& Arbab, F. (2004). Coordinating Web Services Using Channel Based Communication. Paper presented at the Computer Software and Applications Conference (COMPSAC).

45. Lind, M., \& Goldkuhl, G. (1997). Reconstruction of Different Business Processes - A Theory and Method Driven Analysis. Paper presented at the International Working Conference on the LanguageAction Perspective on Communication Modelling (LAP), Eindhoven University of Technology.

46. Lind, M., \& Goldkuhl, G. (2001). Generic Layered Patterns for Business Modelling. International Working Conference on the Language-Action Perspective on Communication Modelling (LAP).

47. Ljungberg, J., \& Holm, P. (1997). Speech Acts On Trial. In L. Mathiassen (Ed.), Computers and Design in Context (pp. 317-348): The MIT Press.

48. Lyytinen, K. (2004). The Struggle with the Language in the IT - Why is LAP not in the Mainstream? Paper presented at the International Working Conference on the Language-Action Perspective on Communication Modelling (LAP), New Brunswick, NJ.

49. Lyytinen, K., Lehitnen, E., \& Auramäki, E. (1987). SAMPO: a speech-act based office modelling approach. ACM SIGOIS Bulletin, 8(4), 11-23.

50. Manes, A. T. (2003). Web Services: A Manager's Guide: Addison-Wesley Professional.

51. Medina-Mora, R., Winograd, T., Flores, R., et al. (1992). The action workflow approach to workflow management technology. Paper presented at the ACM conference on Computer-supported cooperative work, Toronto, Ontario, Canada.

52. Moore, S. A. (2000). On Conversation Policies and the Need for Exceptions. In F. Dignum \& M. Greaves (Eds.), Issues in Agent Communication (Vol. 1916, pp. 144-159): Springer-Verlag.

53. Moore, S. A. (2001). A Foundation for Flexible Automated Electronic Communication. Information Systems Research, 12(1), 34-62.

54. Mukhi, N. K., Plebani, P., SilvaLepe, I., et al. (2004). Supporting policy-driven behaviors in web services: experiences and issues. Paper presented at the International Conference on Service Oriented Computing (ICSOC), New York, NY, USA.

55. Navathe, S., Elmasri, R., \& Larson, J. (1986). Integrating user views in database design. IEEE Computer, 19(1), 50-62.

56. OASIS. (2005). Organization for the Advancement of Structured Information Standards (OASIS). Retrieved June 6, 2005, from http://www.oasis-open.org/home/index.php

57. OSI. (1994). ISO 7498: Open System Interconnection Model. ACM SIGCOMM.

58. OWL. (2004, 10 February 2004). OWL Web Ontology Language Overview. Retrieved February 27, 2005

59. Paolucci, M., \& Sycara, K. (2004). Semantic Web Services: Current Status and Future Directions. Paper presented at the IEEE International Conference on Web Services (ICWS). 
60. Paolucci, M., Sycara, K., Nishimura, T., et al. (2003). Toward Semantic Web Services. Paper presented at the Workshop on E-Services and the Semantic Web (ESSW), Budapest, Hungary.

61. Papazoglou, M. P., \& Georgakopoulos, D. (2003). Service Oriented Computing. Communications of the ACM, 46(10), 24-28.

62. Rawlins, M. C. (2002, April 25). ebXML - A Critical Analysis. Rawlins EC Consulting.

63. Reijswoud, V. v., \& Lind, M. (1998). Comparing two business modelling approaches in the language action perspective. Paper presented at the International Working Conference on the Language-Action Perspective on Communication Modelling (LAP).

64. Reijswoud, V. v., Mulder, H. B. F., \& Dietz, J. L. G. (1999). Communicative action-based business process and information systems modelling with DEMO. Information Systems Journal, 9(2), 117138.

65. Schoop, M. (2001). An introduction to the language-action perspective. ACM SIGGROUP Bulletin, 22(2), 3 - 8.

66. Schoop, M. (2002). Business Communication in Electronic Commerce. Paper presented at the International Working Conference on the Language-Action Perspective on Communication Modelling (LAP).

67. Schoop, M. (2003). A Language-Action Approach to Electronic Negotiations. International Working Conference on the Language-Action Perspective on Communication Modelling (LAP).

68. Searle, J. (1969). Speech acts: An essay in the philosophy of language. Cambridge, England: Cambridge University Press.

69. Sleeper, B., \& Robins, B. (2001). Defining Web Services. The Stencil Group.

70. SOAP. (2003, 24 June 2003). Simple Object Access Protocol (SOAP) Version 1.2. Retrieved February 19, 2005, from http://www.w3.org/TR/soap12-part1/

71. SWS Arch. (2005, April 2005). Semantic Web Services Architecture. Retrieved June 7, 2005, from http://www.daml.org/services/swsa/note/swsa-note_v5.html

72. SWS Glossary. (2005, May 9, 2005). Semantic Web Services Glossary. Retrieved October 31, 2005, from http://www.daml.org/services/swsf/1.0/overview/\#sec-glossary

73. SWSL. (2005). Semantic Web Services Language (SWSL). Retrieved February 27, 2005, from http://www.daml.org/services/swsl/index.html

74. Turner, M., Budgen, D., \& Brereton, P. (2003). Turning software into a service. IEEE Computer Society, 36(10), 38 - 44.

75. UDDI. (2005, January 19, 2004). Universal Description Discovery and Integration (UDDI). Retrieved February 19, 2005, from http://uddi.org/pubs/uddi-v3.0.2-20041019.htm

76. Umapathy, K., Purao, S., \& Sugumaran, V. (2003). Facilitating Conversations among Web Services as Speech-act based Discourses. Paper presented at the Workshop on Information Technologies and Systems, Seattle, WA, USA.

77. Verharen, E., Dignum, F., \& Weigand, H. (1996). A Language/Action Perspective on Cooperative Information Agents. Proceedings of the First International Workhshop on Communication Modeling.

78. Weigand, H., Heuvel, W.-J. v. d., \& Dignum, F. (1998). Modelling Electronic Commerce Transaction - A Layered Approach. Paper presented at the International Working Conference on the LanguageAction Perspective on Communication Modelling (LAP). 
79. Winograd, T., \& Flores, F. (1986). Understanding Computers and Cognition: A New Foundation for Design. Boston, USA: Addison-Wesley Professional.

80. WS Activity. (2005, January 28, 2005). Web Services Activity Statement. Retrieved February 19, 2005, from http://www.w3.org/2002/ws/Activity

81. WS Arch. (2005, 11 February 2004). Web Services Architecture. Retrieved February 17, 2005, from http://www.w3.org/TR/2004/NOTE-ws-arch-20040211/

82. WS Glossary. (2004, 11 February 2004). Web Services Glossary. Retrieved October 31, 2005, from http://www.w3.org/TR/ws-gloss/

83. WS SWSIG. (2002). Semantic Web Services Interest Group. Retrieved June 6, 2005, from http://www.w3.org/2002/ws/swsig/

84. WS-Addressing. (2005). Web Services Addressing (WS-Addressing). Retrieved April 12, 2005, from http://www.w3.org/2002/ws/addr/

85. WS-BPEL. (2005). Web Services Business Process Execution Language (WS-BPEL). Retrieved February 19, 2005, from http://www.oasis-open.org/committees/tc home.php?wg abbrev=wsbpel

86. WS-CDL. (2004, 17 December 2004). Web Services Choreography Description Language (WSCDL). Retrieved April 11, 2005, from http://www.w3.org/TR/ws-cdl-10/

87. WS-CF. (2004, 22 December 2004). Web Services Coordination Framework Specification (WS-CF). Retrieved May 12, 2005, from http://www.oasis-open.org/committees/download.php/10889/WSCFWorking-12-22.pdf

88. WSCI. (2002, 8 August 2002). Web Service Choreography Interface (WSCI). Retrieved June 6, 2005, from http://www.w3.org/TR/wsci/

89. WSDL. (2001, 15 March). Web Service Description Lanaguage (WSDL). Retrieved February 19, Year, from http://www.w3.org/TR/wsdl

90. WSDM. (2005, March 9). Web Services Distributed Management (WSDM). Retrieved April 12, 2005, from http://www.oasis-open.org/committees/tc_home.php?wg_abbrev=wsdm

91. WS-Reliability. (2004, 24 August). Web Services Reliability (WS-Reliability). Retrieved May 12, 2005, from http://docs.oasis-open.org/wsrm/2004/06/WS-Reliability-CD1.086.pdf

92. WS-Security. (2004, 01, March 2004). Web Services Security: SOAP Message Security (WSSecurity). Retrieved April 13, 2005, from http://docs.oasis-open.org/wss/2004/01/oasis-200401-wsssoap-message-security-1.0.pdf

93. WS-TXM. (2003, July 28). Web Services Transaction Management (WS-TXM). Retrieved May 12, 2005, from http://developers.sun.com/techtopics/webservices/wscaf/wstxm.pdf 


\section{$\underline{\text { Appendix A. Proposed web services standards }}{ }^{6}$}

\begin{tabular}{|c|c|c|c|c|}
\hline Standard & Initiative & Name & Description of the standard & URL \\
\hline BPIM & ebXML & $\begin{array}{l}\text { Business Process } \\
\text { Information Modeling }\end{array}$ & $\begin{array}{l}\text { Specifies aspects of interoperability required for } \\
\text { business processes. }\end{array}$ & $\begin{array}{l}\text { http://www.ebxml.org/specs/bpOVER } \\
\text { _print.pdf }\end{array}$ \\
\hline BPSS & ebXML & $\begin{array}{l}\text { Business Process } \\
\text { Specification Schema }\end{array}$ & $\begin{array}{l}\text { Specifies a configuration to support execution of } \\
\text { (collaborative) business transactions. }\end{array}$ & $\begin{array}{l}\text { http://www.ebxml.org/specs/ebBPSS } \\
\text { _print.pdf }\end{array}$ \\
\hline CPA & ebXML & $\begin{array}{l}\text { Collaborative Protocol } \\
\text { Agreement }\end{array}$ & $\begin{array}{l}\text { Defines the capabilities that two parties need to } \\
\text { agree upon. }\end{array}$ & $\begin{array}{l}\text { http://www.ebxml.org/specs/ebcpp- } \\
\text { 2.0.pdf }\end{array}$ \\
\hline СРP & ebXML & $\begin{array}{l}\text { Collaborative Protocol } \\
\text { Profile }\end{array}$ & $\begin{array}{l}\text { Defines the capabilities of a party to engage in e- } \\
\text { Business with other parties. }\end{array}$ & $\begin{array}{l}\text { http://www.ebxml.org/specs/ebcpp- } \\
\text { 2.0.pdf }\end{array}$ \\
\hline $\begin{array}{l}\text { ebXML } \\
\text { MS }\end{array}$ & ebXML & $\begin{array}{l}\text { ebXML Messaging } \\
\text { Service }\end{array}$ & $\begin{array}{l}\text { Specifics protocol for exchanging secure and } \\
\text { reliable messages. }\end{array}$ & $\begin{array}{l}\text { http://www.ebxml.org/specs/ebMS2.p } \\
\text { df }\end{array}$ \\
\hline $\begin{array}{l}\text { ebXML } \\
\text { RIM }\end{array}$ & ebXML & $\begin{array}{l}\text { ebXML Registry } \\
\text { Information Model }\end{array}$ & $\begin{array}{l}\text { Specifies high-level schema of the ebXML } \\
\text { Registry. }\end{array}$ & $\begin{array}{l}\text { http://www.ebxml.org/specs/ebrim2.p } \\
\text { df }\end{array}$ \\
\hline ebXML RS & ebXML & $\begin{array}{l}\text { ebXML Registry } \\
\text { Services }\end{array}$ & $\begin{array}{l}\text { Specifies a set of services that enable sharing of } \\
\text { information among partners. }\end{array}$ & $\begin{array}{l}\text { http://www.ebxml.org/specs/ebRS_pr } \\
\text { int.pdf }\end{array}$ \\
\hline FTP & All three & File Transfer Protocol & Specifies a protocol to share documents remotely. & http://www.w3.org/Protocols/rfc959/ \\
\hline HTTP & All three & ext Transport & rotocol for distributing and presenting & $\begin{array}{l}\text { w3.org/Protocol } \\
\text { al }\end{array}$ \\
\hline MOWS & W3C & $\begin{array}{l}\text { Management of Web } \\
\text { Services }\end{array}$ & $\begin{array}{l}\text { Defines manageability of web service endpoints } \\
\text { and resources exposed. }\end{array}$ & $\begin{array}{l}\text { http://docs.oasis- } \\
\text { open.org/wsdm/2004/12/wsdm- } \\
\text { mows-1.0.pdf }\end{array}$ \\
\hline MUWS & W3C & $\begin{array}{l}\text { Management Using } \\
\text { Web Services }\end{array}$ & $\begin{array}{l}\text { Defines manageability of a resource exposed via } \\
\text { web services. }\end{array}$ & $\begin{array}{l}\text { http://docs.oasis- } \\
\text { open.org/wsdm/2004/12/wsdm- } \\
\text { muws-part1-1.0.pdf }\end{array}$ \\
\hline OWL & $\begin{array}{l}\text { Semantic } \\
\text { web } \\
\text { services } \\
\end{array}$ & $\begin{array}{l}\text { Ontology Web } \\
\text { Language }\end{array}$ & $\begin{array}{l}\text { Facilitates greater machine interpretability of web } \\
\text { content by providing additional vocabulary along } \\
\text { with a formal semantics. }\end{array}$ & http://www.w3.org/2004/OWL/ \\
\hline $\begin{array}{l}\text { OWL-S } \\
\text { (includes } \\
\text { SWSL and }\end{array}$ & $\begin{array}{l}\text { Semantic } \\
\text { web } \\
\text { services }\end{array}$ & $\begin{array}{l}\text { OWL-based Web } \\
\text { Service Ontology }\end{array}$ & $\begin{array}{l}\text { Describes service profile, service model and } \\
\text { service grounding. }\end{array}$ & $\begin{array}{l}\text { http://www.w3.org/Submission/OWL } \\
\text {-S/ }\end{array}$ \\
\hline
\end{tabular}

${ }^{6}$ Compiled, October 2005. Glossaries of terms used for web services following the three initiatives are available elsewhere: W3C initiative (WS Glossary, 2004); Semantic web services initiative (SWS Glossary, 2005); and ebXML (ebXML Glossary, 2001). 


\begin{tabular}{|c|c|c|c|c|}
\hline Standard & Initiative & Name & Description of the standard & URL \\
\hline \multicolumn{5}{|l|}{$\begin{array}{l}\text { SWSL- } \\
\text { Rules) }\end{array}$} \\
\hline SOAP & All three & $\begin{array}{l}\text { Simple Object Access } \\
\text { Protocol }\end{array}$ & $\begin{array}{l}\text { Specifies protocol for exchanging structured } \\
\text { information in a decentralized, distributed } \\
\text { environment. }\end{array}$ & http://www.w3.org/TR/soap/ \\
\hline UDDI & W3C & $\begin{array}{l}\text { Universal Description, } \\
\text { Discovery and } \\
\text { Integration } \\
\end{array}$ & $\begin{array}{l}\text { Defines a set of services supporting the } \\
\text { description and discovery of web services. }\end{array}$ & $\begin{array}{l}\text { http://www.oasis- } \\
\text { open.org/committees/tc_home.php?w } \\
\text { g_abbrev=uddi-spec }\end{array}$ \\
\hline $\begin{array}{l}\text { WS- } \\
\text { Addressing }\end{array}$ & W3C & $\begin{array}{l}\text { Web Services } \\
\text { Addressing }\end{array}$ & $\begin{array}{l}\text { Defines a set of abstract properties to facilitate } \\
\text { end-to-end addressing of endpoints in messages. }\end{array}$ & http://www.w3.org/TR/ws-addr-core/ \\
\hline WS-BPEL & W3C & $\begin{array}{l}\text { Web Services Business } \\
\text { Process Executing } \\
\text { Language }\end{array}$ & $\begin{array}{l}\text { Defines a formal language to specify business } \\
\text { processes and business interactions. }\end{array}$ & $\begin{array}{l}\text { http://www.oasis- } \\
\text { open.org/committees/tc_home.php?w } \\
\text { g_abbrev=wsbpel }\end{array}$ \\
\hline WS-CDL & W3C & $\begin{array}{l}\text { Web Services } \\
\text { Choreography } \\
\text { Description Language }\end{array}$ & $\begin{array}{l}\text { Defines a formal language to specify external } \\
\text { observable behavior as the presence or absence of } \\
\text { messages that are exchanged among web services. }\end{array}$ & http://www.w3.org/TR/ws-chor-reqs/ \\
\hline WS-CF & W3C & $\begin{array}{l}\text { Web Services } \\
\text { Coordination } \\
\text { Framework }\end{array}$ & $\begin{array}{l}\text { Specifies a mechanism for coordination of } \\
\text { transactions among web services. }\end{array}$ & $\begin{array}{l}\text { http://www.oasis- } \\
\text { open.org/committees/tc_home.php?w } \\
\text { g_abbrev=ws-caf }\end{array}$ \\
\hline $\begin{array}{l}\text { WS } \\
\text { Context }\end{array}$ & W3C & Web Services Context & $\begin{array}{l}\text { Defines a mechanism to share context of an } \\
\text { activity across multiple execution endpoints. }\end{array}$ & $\begin{array}{l}\text { http://www.oasis- } \\
\text { open.org/committees/tc_home.php?w } \\
\text { g_abbrev=ws-caf }\end{array}$ \\
\hline WSDL & W3C & $\begin{array}{l}\text { Web Services } \\
\text { Description Language }\end{array}$ & $\begin{array}{l}\text { Defines a formal language to describe the abstract } \\
\text { functionality as well as the concrete details of a } \\
\text { service. }\end{array}$ & http://www.w3.org/TR/wsdl20/ \\
\hline $\begin{array}{l}\text { WS- } \\
\text { Security }\end{array}$ & W3C & Web Services Security & $\begin{array}{l}\text { Specifies a mechanism to provide message } \\
\text { integrity and confidentiality for SOAP messages. }\end{array}$ & $\begin{array}{l}\text { http://www.oasis- } \\
\text { open.org/committees/tc_home.php?w } \\
\text { g_abbrev=wss }\end{array}$ \\
\hline WS-Topics & W3C & Web Services Topics & $\begin{array}{l}\text { Defines topic expression dialects and metadata } \\
\text { associated with the web services notification } \\
\text { system. }\end{array}$ & $\begin{array}{l}\text { http://docs.oasis- } \\
\text { open.org/wsn/2004/06/wsn-WS- } \\
\text { Topics-1.2-draft-01.pdf }\end{array}$ \\
\hline WS-TXM & W3C & $\begin{array}{l}\text { Web Services } \\
\text { Transaction } \\
\text { Management }\end{array}$ & $\begin{array}{l}\text { Specifies a suite of transaction models, each } \\
\text { suited to solving a different problem domain. }\end{array}$ & $\begin{array}{l}\text { http://www.oasis- } \\
\text { open.org/committees/tc_home.php?w } \\
\text { g_abbrev=ws-caf }\end{array}$ \\
\hline
\end{tabular}

